\title{
Parameter Selection to Ensure Multi-Criteria Optimization of the Taguchi Method Combined with the Data Envelopment Analysis-based Ranking Method when Milling SCM440 Steel
}

\author{
Nguyen Lam Khanh \\ Faculty of Mechanical Engineering \\ University of Transport and Communications \\ Hanoi, Vietnam \\ khanh_mxd@utc.edu.vn
}

\author{
Nguyen Van Cuong \\ Faculty of Mechanical Engineering \\ University of Transport and Communications \\ Hanoi, Vietnam \\ nguyencuong@utc.edu.vn
}

\begin{abstract}
SCM440 steel is a commonly used material for making plastic injection molds and components such as gears, transmission shafts, rolling pins, etc. Surface roughness has a direct influence on the workability and durability of the parts and/or components, while the Material Removal Rate (MRR) is a parameter that is used to evaluate the productivity of the machining process. Furnished products with small surface roughness and large MRR is the desired result by all milling processes. In this paper, the determination of the values of input parameters is studied in order to ensure that during the process of milling SCM440 steel, it will have the smallest surface roughness and the largest MRR. There are five parameters that are required to be determined, namely the cutting insert material, the tool nose radius, the cutting speed, the feed rate, and the cutting depth. The Taguchi method was applied to design the experimental matrix with a total of 27 experiments. Result analysis determined the influence of the input parameters on surface roughness and MRR. The Data Envelopment Analysisbased Ranking (DEAR) method was applied to determine the optimal value of the input parameters, which were used to conduct the milling experiments to re-evaluate their suitability.
\end{abstract}

Keywords-milling; SCM440 steel; surface roughness; MRR; optimization; Taguchi; DEAR

\section{INTRODUCTION}

Milling is a very common machining method in the mechanical engineering industry. It is considered to be the cutting method with the highest productivity. With the development of the cutting tool manufacturing technology as well as the emergence of the modern $\mathrm{CNC}$ machines, this method is capable of ensuring very high accuracy. Research of solutions that improve the accuracy of milling machines and milling cutters is continuously conducted [1]. Therefore, in some cases, this method is used as the final machining method for surfaces requiring high precision [2]. To make the most use of the achievements in the mechanical engineering technology and the cutting tool manufacturing technology, many researchers carried out experimental studies to determine the optimal value of parameters related to the machining process.
The purpose of these studies is to determine the value of the machining process's parameters to ensure minimum surface roughness and maximum Material Removal Rate (MRR). This problem is known as milling operations optimization. When studying the milling operations optimization, many authors used the Taguchi method to design the experimental matrix. When comparing the Taguchi-based matrix design method with some other matrix design methods, it was found that the Taguchi method requires a smaller number of experiments. An advantage that only the Taguchi method possesses is that it can design a matrix with the input parameters being a qualitative (not a quantitative) parameter $[3,4]$.

In [5], the Taguchi method was applied to design the experimental matrix when milling the AA6082T6 material by a tungsten carbide cutting tool. Signal-to-Noise $(\mathrm{S} / \mathrm{N})$ ratio was analyzed to determine the optimal values of spindle speed, feed rate, and depth of cut to ensure the minimum value of surface roughness. The Taguchi method was also used to design the experimental matrix when milling AA6082T6 with PVDcoated and CVD-coated cutting tools. The determination of cutting speed, feed rate, and tool material type to ensure tool wear was similarly performed for surface roughness in [6]. In [7], the authors applied the Taguchi method to design the experimental matrix when milling D2 steel with the carbide inserts cutting tool. Cutting parameters including spindle speed, feed rate, and depth of cut were selected as input parameters for each experiment. The $\mathrm{S} / \mathrm{N}$ ratio analysis method was applied to determine the optimal value of the cutting parameters to ensure the minimum value of surface roughness. When milling AISI P20 steel with the carbide inserts cutting tool, the authors in [8] used the Taguchi method to design an experimental matrix with spindle speed, feed rate, and depth of cut as input parameters [8]. They also used $\mathrm{S} / \mathrm{N}$ ratio analysis to determine the optimal value of the input parameters to ensure the minimum value of surface roughness. To determine the optimal value of parameters including cutting speed, feed, radial depth, and axial depth to ensure the minimum value of surface roughness when milling 1.2738 steel with the WNHU 04T310 cutting tool 
(manufactured by Palbit), the authors in [9] also applied the Taguchi method to design the experimental matrix. The $\mathrm{S} / \mathrm{N}$ ratio analysis method was applied to determine the optimal value of the cutting parameters. Authors in [10] also designed the experimental matrix according to the Taguchi method when milling 7075T6 aluminum alloy with an AlTiN PVD-coated cutting tool. The optimal values of cutting speed, feed rate, radial depth, and axial depth were also determined by the analysis of the $\mathrm{S} / \mathrm{N}$ ratio. This study also aimed to ensure the minimum value of surface roughness. To determine the optimum value of cutting speed, feed rate, depth of cut, and coolant flow to ensure the minimum value of surface roughness when milling AISI 1040 MS steel with the carbide inserts cutting tool, the authors in [11] also designed the experimental matrix according to the Taguchi method and the $\mathrm{S} / \mathrm{N}$ ratio analysis method was also used to determine the optimal value of the input parameters. Authors in [12] also designed the experimental matrix according to the Taguchi method when milling 7075 T6 aluminum alloy with a High-Speed Steel (HSS) cutting tool. They also applied the $\mathrm{S} / \mathrm{N}$ ratio analysis method to determine two sets of optimal values of cutting speed, feed rate, and depth of cut, one set that ensures the smallest surface roughness and another set that ensures the largest MRR.

The experimental matrix design based on the Taguchi method has been successfully applied in a number of studies to ensure a certain criterion of the machining process. However, if only the Taguchi method is applied for the experimental design and the $\mathrm{S} / \mathrm{N}$ ratio analysis to determine the optimal value of the machining process parameters, only one criterion of the machining process can be guaranteed. In order to resolve this shortcoming of the Taguchi method, many studies combined the Taguchi method with other methods to optimize the multiobjectives of the milling process: in [13], the Taguchi method has been combined with ANOVA to determine the values of the spindle speed, the feed rate and the cutting depth to ensure the minimum surface roughness and the maximum MRR when milling AISI 1005 steel with the TiN coated cutting tool. In [14], the Taguchi method and the Weighted Principal Component Analysis (WPCA) were combined to determine the milling type and the values of milling parameters to simultaneously ensure minimum surface roughness and maximum MRR when milling Al 6061 aluminum alloy with a high speed steel cutting tool. The Taguchi method and the Gray Relational Analysis (GRA) method were combined to determine the values of cutting speed, feed rate, and cutting depth to ensure simultaneously minimum surface roughness and maximum MRR when milling Inconel 718 super alloy by an uncoated tungsten carbide cutting tool in [15]. A combination of the Taguchi method, TOPSIS method, and ANOVA analysis was performed to determine the optimal values of cutting speed, feed rate, and depth of cut to ensure simultaneously the minimum value of surface roughness and maximum value of MRR when milling Ti-6Al-4V titanium alloy with TiN coated cutting tools in [16]. Through the above studies, it is shown that the cutting tool parameters are commonly selected as the input parameters of the milling experiment process. These parameters can be easily adjusted by the operators. However, to the best of our knowledge, there have been no studies that consider all the 5 parameters of the cutting tool material, i.e. the insert material, the tool nose radius, the cutting speed, the feed rate, and the depth of cut.

SCM440 steel is a type of steel used quite commonly to make plastic injection molds and components such as gears, transmission shafts, and rolling pins [17]. Due to the high content of $\mathrm{Cr}$, Mo and $\mathrm{Mn}$ elements, this steel has a low thermal conductivity. When machining this steel, the tool wears out quickly, thus it is required to select the right cutting tool [18-20]. A number of studies on milling steels equivalent to this steel have been carried out [17-23]. However, to the best of our knowledge, there are no published studies on milling SCM440 (or equivalent) steel that consider all 5 parameters. DEAR is a method used for multi-criteria decision making that was introduced in 2002 [24]. This method has been used for the multi-objective optimization of the AISI 1055 steel turning process [25], the Ti-6Al-4V alloy turning process [26], the SAE420 steel grinding with a segmented grinding wheel [27], of the Electrical Discharge Machining (EDM) with the material type AA 6082 [26], etc. However, to the best of our knowledge, there have been no published studies on the application of this method in multi-criteria decision making for milling methods in general and for milling SCM440 steel in particular.

In this study, milling parameters such as the cutting tool material, the tool nose radius, the cutting speed, the feed rate, and the cutting depth will be determined to simultaneously ensure the optimization of two criteria, minimum surface roughness and maximum MRR when milling this type of steel. A combination of the Taguchi method and the DEAR method was used to solve this problem.

\section{THE DEAR METHOD}

The purpose of the experimental process of this study is to ensure that surface roughness $(R a)$ has the smallest value and the $M R R$ reaches the maximum value. Thus, it is required to determine the values of the input parameters that ensure the set out objectives. The DEAR method will be applied in this study to carry out the above-stated work [24]. The DEAR method's steps are [24]:

- Determine the weight of each response for all experiments. This value is calculated as the ratio of the value of each response to the sum of all responses.

- Transfer the response data to the weight data by multiplying the observed data by their respective weight.

- Divide the inversed data by the sum of all inversed data.

- The Multi Response Performance Index (MRPI) is calculated by (1):

$$
M R P I=W_{R_{a}} * R_{a}+W_{M R R} * M R R
$$

The weights of the responses are calculated as:

$$
\begin{gathered}
W_{R_{a}}=\frac{R_{a}}{\sum R_{a}} \\
W_{M R R}=\frac{\frac{1}{M R R}}{\sum \frac{1}{M R R}}
\end{gathered}
$$




\section{EXPERIMENTS ON MILLING SCM400 STEEL}

\section{A. Experimental System}

A CNC milling machine with the HAA5 serial was used to carry out the experiments (Figure 1). The experimental sample is SCM400 steel with length, width, and height of $80 \mathrm{~mm}$, $40 \mathrm{~mm}$, and $30 \mathrm{~mm}$ respectively. The steel's chemical composition conducted with a spectrometer was: $0.43 \% \mathrm{C}$, $0.28 \% \mathrm{Si}, 0.72 \% \mathrm{Mn}, 1.05 \% \mathrm{Cr}, 0.23 \% \mathrm{Mo}, 0.024 \% \mathrm{P}$, and $0.026 \% \mathrm{~S}$.

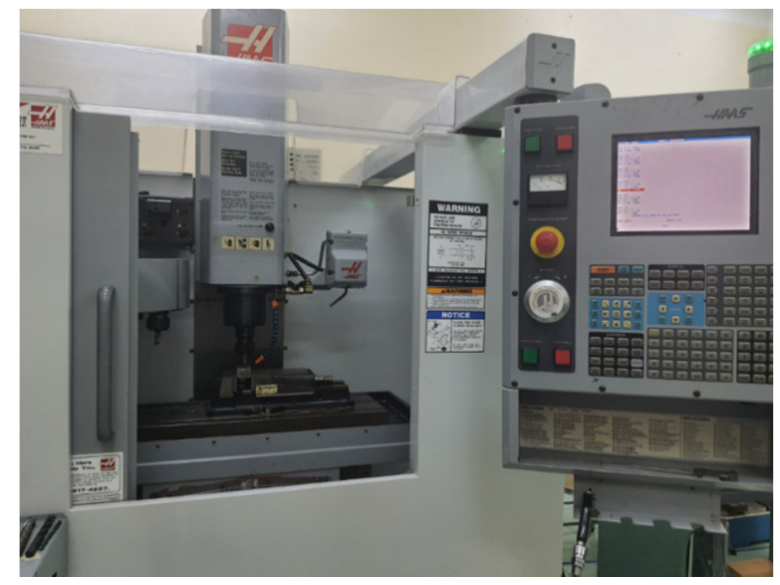

Fig. 1. The milling machine.

TABLE I. PARAMETERS OF THE CUTTING INSERTS

\begin{tabular}{|c|c|c|c|}
\hline \multirow{2}{*}{ Parameter } & \multicolumn{3}{|c|}{ Cutting insert } \\
\cline { 2 - 4 } & $\begin{array}{c}\text { R390- } \\
\text { 11T303M } \\
\text {-PM1025 }\end{array}$ & $\begin{array}{c}\text { R390- } \\
\mathbf{1 1 T 3 0 5 M -} \\
\text { PM1025 }\end{array}$ & $\begin{array}{c}\text { R390- } \\
\mathbf{1 1 T 3 0 5 M} \\
\text {-PM1025 }\end{array}$ \\
\hline Tool nose radius (mm) & 0.3 & 0.5 & 0.8 \\
\hline Back edge length (mm) & 0.8 & 0.9 & 1.2 \\
\hline Weight (kg) & 0.0022 & 0.0026 & 0.003 \\
\hline Coating material & \multicolumn{3}{|c|}{ TiN; TiCN; TiAlN } \\
\hline Cutting thickness (mm) & \multicolumn{3}{|c|}{3.59} \\
\hline Main cutting angle (degree) & \multicolumn{3}{|c|}{10} \\
\hline Maximum cutting depth (mm) & \multicolumn{3}{|c|}{6.8} \\
\hline Shape style of cutting piece & \multicolumn{3}{|c|}{10} \\
\hline Edge width (mm) & \multicolumn{3}{|c|}{} \\
\hline Effective length of edge (mm) & \multicolumn{3}{|c|}{} \\
\hline
\end{tabular}

Three types of cutting pieces were used in the experiment namely the TiN-, TiCN-, and TiAlN-coated pieces. These cutting pieces have high thermal resistance, and have been proven to be very suitable for machining SCM440 steel. Each cutting piece was used with 3 tool nose radius values of $0.3 \mathrm{~mm}, 0.5 \mathrm{~mm}$, and $0.8 \mathrm{~mm}$. On the tool shank with $12 \mathrm{~mm}$ diameter, 2 symmetrical cutting pieces were installed. Each cutting insert was used only once for the purpose of eliminating the influence of tool wear on the output parameters of the milling process. In other words, the number of cutting inserts used in the experiment is twice the number of experiments to be carried out. The milling process has been carried out according to the method of symmetric milling, which means that the milling width was equal to the diameter of the milling cutter. Table I shows some basic parameters of the cutting inserts used.
The surface roughness was measured with a Mitutoyo Japan SJ301 surface roughness tester of $0.8 \mathrm{~mm}$ standard length. The surface roughness of each experimental sample was determined by averaging at least three consecutive measurements. The MRR was calculated according to:

$$
M R R=V_{f} \cdot a_{p} \cdot b_{w}\left(\mathrm{~mm}^{3} / \mathrm{min}\right)
$$

where $V_{f}$ is the feed rate $(\mathrm{mm} / \mathrm{min}), a_{p}$ is the cutting depth $(\mathrm{mm})$, and $b_{w}$ is the cutting width ( $\left.\mathrm{mm}\right)$. In this case the cutting width is just equal to the diameter of the milling cutter.

\section{B. Experimental Design}

The Taguchi method was applied to design the experimental process in this study. Five parameters were selected as the input parameters of the experimental process,. Each selected parameter has three levels of values (corresponding to three encoding degrees of 1, 2, and 3). The values of the experimental parameters, selected within their range as recommended by the cutting tool manufacturer [29], are shown in Table II.

TABLE II. INPUT PARAMETERS

\begin{tabular}{|c|c|c|c|c|c|}
\hline \multirow{2}{*}{ Parameter } & \multirow{2}{*}{ Symbol } & \multirow{2}{*}{ Unit } & \multicolumn{3}{|c|}{ Value at level } \\
\cline { 4 - 6 } & & & $\mathbf{1}$ & $\mathbf{2}$ & $\mathbf{3}$ \\
\hline Insert material & $\boldsymbol{M}$ & - & TiN & TiCN & TiAIN \\
\hline Tool nose radius & $r$ & $\mathrm{~mm}$ & 0.3 & 0.5 & 0.8 \\
\hline Cutting speed & $V_{c}$ & $\mathrm{~m} / \mathrm{min}$ & 80 & 120 & 160 \\
\hline Feed rate & $V_{f}$ & $\mathrm{~mm} / \mathrm{min}$ & 250 & 320 & 390 \\
\hline Depth of cut & $a_{p}$ & $\mathrm{~mm}$ & 0.20 & 0.30 & 0.40 \\
\hline
\end{tabular}

The Taguchi method was used to design the experimental matrix. When comparing the matrix design method by the Taguchi method with some other matrix design methods, it can be found that it requires a smaller number of experiments. For example, with 5 input parameters, in which each parameter has 3 levels of values, the Taguchi method only needs 27 experiments while the Box-Behnken design needs at least 46 experiments and the Central Composite Design (CCD) method needs a minimum of 43 experiments. An advantage that only the Taguchi method obtains is that it allows designing the experimental matrix with input parameters that are not quantitative parameters. In this case the qualitative parameter is just the cutting insert material type. So, the experimental matrix was designed according to the Taguchi method with a total of 27 experiments, as shown in Table III.

\section{RESULTS AND DISCUSSION}

The experiments in Table III are given in accordance with the results shown in Table IV. Figure 2 shows the influence of the input parameters on surface roughness. The comparison of the difference at the lowest and highest levels, i.e. between level 1 and level 3 of the parameter line graph (red broken line) shows that the tool nose radius is the parameter that has the greatest influence on surface roughness, followed by the influence of the cutting insert material and the feed rate. The difference of the line graph of cutting speed and cutting depth is very small, showing that these two parameters have negligible influence on surface roughness. 
TABLE III. EXPERIMENTAL MATRIX

\begin{tabular}{|c|c|c|c|c|c|c|c|c|c|c|}
\hline \multirow{2}{*}{ No. } & \multicolumn{5}{|c|}{ Code value } & \multicolumn{5}{|c|}{ Actual value } \\
\hline & $I M$ & $r$ & $V_{c}$ & $V_{f}$ & $a_{p}$ & $I M$ & $r(m m)$ & $V_{c}(\mathrm{~m} / \mathrm{min})$ & $V_{f}(\mathrm{~mm} / \mathrm{min})$ & $a_{p}(m m)$ \\
\hline 1 & 1 & 1 & 1 & 1 & 1 & TiN & 0.3 & 80 & 250 & 0.2 \\
\hline 2 & 1 & 1 & 1 & 1 & 2 & $\mathrm{TiN}$ & 0.3 & 80 & 250 & 0.4 \\
\hline 3 & 1 & 1 & 1 & 1 & 3 & TiN & 0.3 & 80 & 250 & 0.6 \\
\hline 4 & 1 & 2 & 2 & 2 & 1 & TiN & 0.5 & 120 & 320 & 0.2 \\
\hline 5 & 1 & 2 & 2 & 2 & 2 & TiN & 0.5 & 120 & 320 & 0.4 \\
\hline 6 & 1 & 2 & 2 & 2 & 3 & TiN & 0.5 & 120 & 320 & 0.6 \\
\hline 7 & 1 & 3 & 3 & 3 & 1 & TiN & 0.8 & 160 & 390 & 0.2 \\
\hline 8 & 1 & 3 & 3 & 3 & 2 & $\mathrm{TiN}$ & 0.8 & 160 & 390 & 0.4 \\
\hline 9 & 1 & 3 & 3 & 3 & 3 & TiN & 0.8 & 160 & 390 & 0.6 \\
\hline 10 & 2 & 1 & 2 & 3 & 1 & TiCN & 0.3 & 120 & 390 & 0.2 \\
\hline 11 & 2 & 1 & 2 & 3 & 2 & TiCN & 0.3 & 120 & 390 & 0.4 \\
\hline 12 & 2 & 1 & 2 & 3 & 3 & TiCN & 0.3 & 120 & 390 & 0.6 \\
\hline 13 & 2 & 2 & 3 & 1 & 1 & TiCN & 0.5 & 160 & 250 & 0.2 \\
\hline 14 & 2 & 2 & 3 & 1 & 2 & TiCN & 0.5 & 160 & 250 & 0.4 \\
\hline 15 & 2 & 2 & 3 & 1 & 3 & TiCN & 0.5 & 160 & 250 & 0.6 \\
\hline 16 & 2 & 3 & 1 & 2 & 1 & TiCN & 0.8 & 80 & 320 & 0.2 \\
\hline 17 & 2 & 3 & 1 & 2 & 2 & $\mathrm{TiCN}$ & 0.8 & 80 & 320 & 0.4 \\
\hline 18 & 2 & 3 & 1 & 2 & 3 & $\mathrm{TiCN}$ & 0.8 & 80 & 320 & 0.6 \\
\hline 19 & 3 & 1 & 3 & 2 & 1 & TiAlN & 0.3 & 160 & 320 & 0.2 \\
\hline 20 & 3 & 1 & 3 & 2 & 2 & TiAlN & 0.3 & 160 & 320 & 0.4 \\
\hline 21 & 3 & 1 & 3 & 2 & 3 & TiAlN & 0.3 & 160 & 320 & 0.6 \\
\hline 22 & 3 & 2 & 1 & 3 & 1 & TiAlN & 0.5 & 80 & 390 & 0.2 \\
\hline 23 & 3 & 2 & 1 & 3 & 2 & TiAlN & 0.5 & 80 & 390 & 0.4 \\
\hline 24 & 3 & 2 & 1 & 3 & 3 & TiAlN & 0.5 & 80 & 390 & 0.6 \\
\hline 25 & 3 & 3 & 2 & 1 & 1 & TiAlN & 0.8 & 120 & 250 & 0.2 \\
\hline 26 & 3 & 3 & 2 & 1 & 2 & TiAlN & 0.8 & 120 & 250 & 0.4 \\
\hline 27 & 3 & 3 & 2 & 1 & 3 & TiAlN & 0.8 & 120 & 250 & 0.6 \\
\hline
\end{tabular}

TABLE IV. EXPERIMENTAL RESULTS

\begin{tabular}{|c|c|c|c|c|c|c|c|}
\hline No & $I M$ & $r(\mathrm{~mm})$ & $V_{c}(\mathrm{~m} / \mathrm{min})$ & $V_{f}(\mathrm{~mm} / \mathrm{min})$ & $a_{p}(\mathbf{m m})$ & $R a(\mu \mathrm{m})$ & $\operatorname{MRR}\left(\mathrm{mm}^{3} / \mathrm{min}\right)$ \\
\hline 1 & TiN & 0.3 & 80 & 250 & 0.2 & 0.771 & 600 \\
\hline 2 & TiN & 0.3 & 80 & 250 & 0.4 & 1.457 & 1200 \\
\hline 3 & TiN & 0.3 & 80 & 250 & 0.6 & 1.697 & 1800 \\
\hline 4 & TiN & 0.5 & 120 & 320 & 0.2 & 1.538 & 768 \\
\hline 5 & TiN & 0.5 & 120 & 320 & 0.4 & 0.905 & 1536 \\
\hline 6 & TiN & 0.5 & 120 & 320 & 0.6 & 0.986 & 2304 \\
\hline 7 & TiN & 0.8 & 160 & 390 & 0.2 & 2.205 & 936 \\
\hline 8 & TiN & 0.8 & 160 & 390 & 0.4 & 1.582 & 1872 \\
\hline 9 & TiN & 0.8 & 160 & 390 & 0.6 & 0.863 & 2808 \\
\hline 10 & $\mathrm{TiCN}$ & 0.3 & 120 & 390 & 0.2 & 1.024 & 936 \\
\hline 11 & $\mathrm{TiCN}$ & 0.3 & 120 & 390 & 0.4 & 1.112 & 1872 \\
\hline 12 & TiCN & 0.3 & 120 & 390 & 0.6 & 0.801 & 2808 \\
\hline 13 & TiCN & 0.5 & 160 & 250 & 0.2 & 1.076 & 600 \\
\hline 14 & TiCN & 0.5 & 160 & 250 & 0.4 & 2.908 & 1200 \\
\hline 15 & TiCN & 0.5 & 160 & 250 & 0.6 & 1.014 & 1800 \\
\hline 16 & TiCN & 0.8 & 80 & 320 & 0.2 & 0.985 & 768 \\
\hline 17 & $\mathrm{TiCN}$ & 0.8 & 80 & 320 & 0.4 & 3.019 & 1536 \\
\hline 18 & TiCN & 0.8 & 80 & 320 & 0.6 & 1.549 & 2304 \\
\hline 19 & TiAlN & 0.3 & 160 & 320 & 0.2 & 0.927 & 768 \\
\hline 20 & TiAlN & 0.3 & 160 & 320 & 0.4 & 0.877 & 1536 \\
\hline 21 & TiAlN & 0.3 & 160 & 320 & 0.6 & 0.892 & 2304 \\
\hline 22 & TiAlN & 0.5 & 80 & 390 & 0.2 & 1.234 & 936 \\
\hline 23 & TiAlN & 0.5 & 80 & 390 & 0.4 & 1.929 & 1872 \\
\hline 24 & TiAlN & 0.5 & 80 & 390 & 0.6 & 0.824 & 2808 \\
\hline 25 & TiAlN & 0.8 & 120 & 250 & 0.2 & 0.545 & 600 \\
\hline 26 & TiAlN & 0.8 & 120 & 250 & 0.4 & 1.549 & 1200 \\
\hline 27 & TiAlN & 0.8 & 120 & 250 & 0.6 & 1.601 & 1800 \\
\hline
\end{tabular}

Because the cutting insert material, the tool nose radius and the cutting speed do not exist in the MRR calculation formula (4), they have no influence on MRR. Figure 3 shows the influence of the feed rate and the cutting depth on MRR. The difference between level 1 and level 3 of cutting depth line graph is greater than the one of the feed rate line graph. This 
shows that the cutting depth has a greater influence on MRR than the feed rate. Thus, we see that the influence of the input parameters on surface roughness and MRR is different, even adverse, e.g. the tool nose radius has a great influence on surface roughness without any influence on MRR, the feed rate and the cutting depth are two parameters needed for calculating the MRR, but they do not significantly affect surface roughness, etc. Thus, it can be said that being based only on the two graphs of Figures 2 and 3, limits the determination of the values of the input parameters to ensure minimum surface roughness and maximum MRR. Table IV shows that surface roughness has the smallest value in experiment $\# 25$, while MRR has the maximum value in experiments \#9, \#12 and \#24. Thus, if we only observe Table IV, it is not possible to determine the value of the input parameters to ensure both minimum surface roughness and maximum MRR. The DEAR method will be used to solve this problem in the next section.
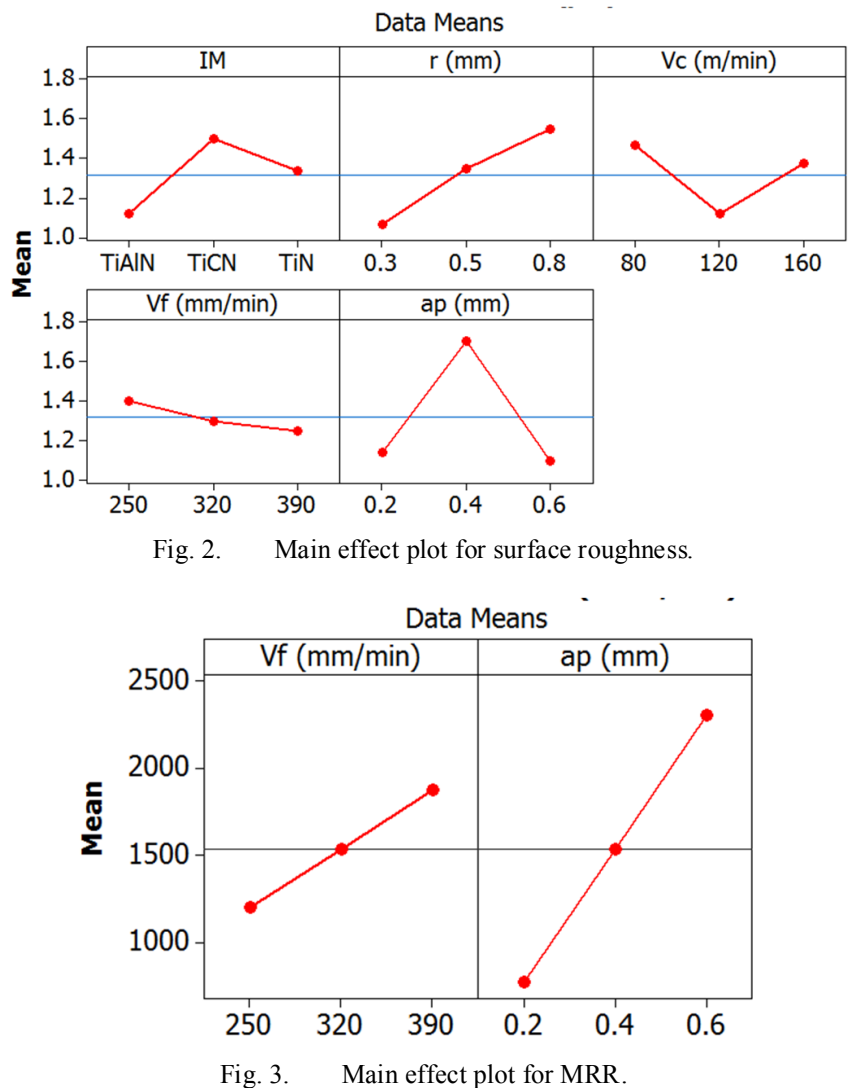

\section{SElection OF the VAlue OF THE INPUT PARAMETERS}

From the experimental data in Table IV, the weights of the responses and the MRPI value at each experiment are calculated according to (1) - (3), as shown in Table V. From the data in Table V, the MRPI values of all input parameters at all degrees were calculated. This value is calculated as the sum of the MRPI value of each parameter at the respective degree, as shown in Table VI. From the data in Table VI, it can be seen that the cutting insert material $(I M)$ has the smallest value of MRPI corresponding to level 3, tool nose radius $(r)$ has the smallest value of MRPI corresponding to level 1, cutting speed
$\left(V_{c}\right)$ corresponding to level 2 , and feed rate $\left(V_{f}\right)$ and cutting depth $\left(a_{p}\right)$ corresponding to level 3 . Thus, the optimal value of the parameters of the cutting insert material, the tool nose radius, the cutting speed, the feed rate, and the cutting depth are TiAlN, $0.3 \mathrm{~mm}, \quad 120 \mathrm{~m} / \mathrm{min}, \quad 390 \mathrm{~mm} / \mathrm{min}$, and $0.6 \mathrm{~mm}$ respectively [24]. The MRPI value with the maximum MaxMin of 0.52972 is the cutting depth. Thus, the cutting depth is the parameter that has the greatest influence, followed by the tool nose radius, the cutting insert material, the cutting speed, and the feed rate [24].

TABLE V. EXPERIMENTAL RESPONSE WEIGHT AND MRPI

\begin{tabular}{|c|c|c|c|}
\hline No. & $\boldsymbol{W}_{\boldsymbol{R}_{a}}$ & $\boldsymbol{W}_{\boldsymbol{M R R}}$ & MRPI \\
\hline $\mathbf{1}$ & 0.02168 & 0.07506 & 45.05364 \\
\hline $\mathbf{2}$ & 0.04096 & 0.03753 & 45.09661 \\
\hline $\mathbf{3}$ & 0.04771 & 0.02502 & 45.11789 \\
\hline $\mathbf{4}$ & 0.04324 & 0.05864 & 45.10343 \\
\hline $\mathbf{5}$ & 0.02544 & 0.02932 & 45.05996 \\
\hline $\mathbf{6}$ & 0.02772 & 0.01955 & 45.06426 \\
\hline $\mathbf{7}$ & 0.06199 & 0.04812 & 45.17362 \\
\hline $\mathbf{8}$ & 0.04448 & 0.02406 & 45.10729 \\
\hline $\mathbf{9}$ & 0.02426 & 0.01604 & 45.05787 \\
\hline $\mathbf{1 0}$ & 0.02879 & 0.04812 & 45.06641 \\
\hline $\mathbf{1 1}$ & 0.03126 & 0.02406 & 45.07169 \\
\hline $\mathbf{1 2}$ & 0.02252 & 0.01604 & 45.05497 \\
\hline $\mathbf{1 3}$ & 0.03025 & 0.07506 & 45.06948 \\
\hline $\mathbf{1 4}$ & 0.08175 & 0.03753 & 45.27467 \\
\hline $\mathbf{1 5}$ & 0.02851 & 0.02502 & 45.06584 \\
\hline $\mathbf{1 6}$ & 0.02769 & 0.05864 & 45.06421 \\
\hline $\mathbf{1 7}$ & 0.08487 & 0.02932 & 45.29317 \\
\hline $\mathbf{1 8}$ & 0.04355 & 0.01955 & 45.10439 \\
\hline $\mathbf{1 9}$ & 0.02606 & 0.05864 & 45.06109 \\
\hline $\mathbf{2 0}$ & 0.02466 & 0.02932 & 45.05855 \\
\hline $\mathbf{2 1}$ & 0.02508 & 0.01955 & 45.05930 \\
\hline $\mathbf{2 2}$ & 0.03469 & 0.04812 & 45.07974 \\
\hline $\mathbf{2 3}$ & 0.05423 & 0.02406 & 45.14154 \\
\hline $\mathbf{2 4}$ & 0.01473 & 0.01604 & 45.04465 \\
\hline $\mathbf{2 5}$ & 0.01532 & 0.07506 & 45.04528 \\
\hline $\mathbf{2 6}$ & 0.04355 & 0.03753 & 45.10439 \\
\hline $\mathbf{2 7}$ & 0.04501 & 0.02502 & 45.10899 \\
\hline
\end{tabular}

TABLE VI. TOTAL MRPI

\begin{tabular}{|c|c|c|c|c|}
\hline \multirow{2}{*}{ Parameter } & \multicolumn{3}{|c|}{ Level } & Max - Min \\
\cline { 2 - 5 } & $\mathbf{1}$ & $\mathbf{2}$ & $\mathbf{3}$ & \\
\hline $\boldsymbol{I M}$ & 405.83457 & 406.06482 & 405.70353 & 0.36129 \\
\hline $\boldsymbol{r}$ & 405.64016 & 405.90357 & 406.05920 & 0.41904 \\
\hline $\boldsymbol{V}_{\boldsymbol{c}}$ & 405.99584 & 405.67938 & 405.92771 & 0.31646 \\
\hline $\boldsymbol{V}_{\boldsymbol{f}}$ & 405.93679 & 405.86835 & 405.79778 & 0.13901 \\
\hline $\boldsymbol{a}_{\boldsymbol{p}}$ & 405.71690 & 406.20787 & 405.67815 & 0.52972 \\
\hline
\end{tabular}

\section{EXPERIMENTS WITH THE OPTIMAL VALUES OF THE PARAMETERS}

The optimal set of the 5 input parameters defined above was used to experiment on the milling process with 3 steel samples. The surface roughness of each experimental sample is shown in Table VII. The MRR value at each experiment has also been calculated and is included in this Table. The average value of surface roughness in these cases is $0.724 \mu \mathrm{m}$. If compared with the surface roughness values in Table IV, it can be seen that although $0.724 \mu \mathrm{m}$ is still larger than the value of surface roughness at experiment $\# 25$, this value is very small 
when compared to the total of 27 experiments that were carried out. For MRR, when calculated according to (4), in the three test samples, the MRR is equal to $2808 \mathrm{~mm}^{3} / \mathrm{min}$, which is also larger than the data in Table IV. From that, it can be seen that when machining with the optimal values of the input parameters, MRR reaches its maximum value and surface roughness is also significantly improved. This result ensures the reliability when using the optimal value of the input parameters and proves the success in using the DEAR method in this study.

TABLE VII. OUTPUT PARAMETERS WHEN EXPERIMENTING WITH THE OPTIMAL VALUES OF THE INPUT PARAMETERS

\begin{tabular}{|c|c|c|c|c|c|c|c|}
\hline \multirow{2}{*}{ No. } & \multicolumn{5}{|c|}{ Optimization value } & \multirow{2}{*}{$R a(\mu \mathrm{m})$} & \multirow{2}{*}{$\operatorname{MRR}\left(\mathrm{mm}^{3} / \mathrm{min}\right)$} \\
\hline & IM & $r(\mathrm{~mm})$ & $V_{c}(\mathrm{~m} / \mathrm{min})$ & $V_{f}(\mathrm{~mm} / \mathrm{min})$ & $a_{p}(\mathrm{~mm})$ & & \\
\hline 1 & \multirow{3}{*}{ TiAlN } & \multirow{3}{*}{0.3} & \multirow{3}{*}{120} & \multirow{3}{*}{390} & \multirow{3}{*}{0.6} & 0.726 & 2808 \\
\hline 2 & & & & & & 0.721 & 2808 \\
\hline 3 & & & & & & 0.725 & 2808 \\
\hline \multicolumn{6}{|c|}{ Mean } & 0.724 & 2808 \\
\hline
\end{tabular}

\section{CONCLUSION}

An experimental process of milling SCM 440 steel was carried out in this study. Three types of cutting inserts were used, coated with TiN, TiCN, and TiAlN. The tool nose radius, the cutting speed, the feed rate, and the cutting depth were also determined as input parameters of the experimental process. The DEAR method was applied to determine the optimal value of the input parameters. Some of the conclusions drawn from this study are:

- The tool nose radius is the parameter that has the greatest influence on surface roughness, followed by the influence of the cutting insert material and the feed rate. The cutting speed and the cutting depth have no significant influence on surface roughness.

- Only the feed rate and the cutting depth have an influence on MRR, and the influence of the cutting depth on MRR is greater than the one of the feed rate.

- The parameter set that ensures simultaneously the two objectives is: TiAlN cutting insert material, $0.3 \mathrm{~mm}$ tool nose radius, $120 \mathrm{~mm} / \mathrm{min}$ cutting speed, $390 \mathrm{~mm} / \mathrm{min}$ feed rate, and $0.6 \mathrm{~mm}$ cutting depth.

- DEAR method was not only successful in determining the optimal values of the input parameters in this study as well as in [25-28] but it is also quite promising to being successful in the future when applied to determine the value of input parameters to simultaneously ensure multi-criteria optimization of the machining process.

\section{ACKNOWLEDGMENT}

This research is funded by University of Transport and Communications (UTC) under the grant number T2021-CK003 .

\section{REFERENCES}

[1] J. P. Hung, K. D. Wu, W. Z. Lin, and W. C. Shih, "Analyzing the Dynamic Characteristics of Milling Tool Using Finite Element Method and Receptance Coupling Method," Engineering, Technology \& Applied Science Research, vol. 9, no. 2, pp. 3918-3923, Apr. 2019, https://doi.org/10.48084/etasr.2463

[2] D. D. Trung, "Influence of Cutting Parameters on Surface Roughness during Milling AISI 1045 Steel", Tribology in Industry, vol. 42, no. 4, pp. 658-665, Dec. 2020, https://doi.org/10.24874/ti.969.09.20.11.

[3] M. S. Phadke, Quality Engineering Using Robust Design, Printice Hall, 1989.
[4] S. K. Karna, R. V. Singh, and R. Sahai, "Application of Taguchi Method in Indian Industry", International Journal of Emerging Technology and Advanced Engineering, vol. 2, no. 11, pp. 387-391, 2012.

[5] M. Tamiloli and J. Venkatesan, "Investigation on Effect of Machining Parameters of End Milling on Surface Finish and Temperature Using Taguchi Technique", Journal for Manufacturing Science and Production, vol. 16, no. 4, pp. 255-261, Nov. 2016, https://doi.org/ 10.1515/jmsp-2016-0030.

[6] T. Kivak, "Optimization of surface roughness and flank wear using the Taguchi method in milling of Hadfield steel with PVD and CVD coated inserts", Measurement, vol. 20, pp. 19-28, Apr. 2014, https://doi.org/ 10.1016/j.measurement.2013.12.017.

[7] M. H. F. Al-Hazza, N. A. bt Ibrahim, E. T. Y. Adesta, A. A. Khan, and A. B. A. Sidek, "Surface Roughness Optimization Using Taguchi Method of High Speed End Milling For Hardened Steel D2," IOP Conference Series: Materials Science and Engineering, vol. 184, Mar. Art. no. 012047, 2017, https://doi.org/10.1088/1757-899X/184/1/ 012047.

[8] I. Tlhabadira, I. A. Daniyan, R. Machaka, C. Machio, L. Masu, and L. R. VanStaden, "Modelling and optimization of surface roughness during AISI P20 milling process using Taguchi method," The International Journal of Advanced Manufacturing Technology, vol. 102, no. 9, pp. 3707-3718, Jun. 2019, https://doi.org/10.1007/s00170-019-03452-4.

[9] J. E. Ribeiro, M. B. César, and H. Lopes, "Optimization of machining parameters to improve the surface quanlity," Procedia Structural Integrity, vol. 5, pp. 355-362, Sep. 2017, https://doi.org/10.1016/ j.prostr.2017.07.182.

[10] H. Öktem, T. Erzurumlu, and M. Çöl, "A study of the Taguchi optimization method for surface roughness in finish milling of mold surfaces", The International Journal of Advanced Manufacturing Technology, vol. 28, pp. 694-700, Oct. 2006, https://doi.org/10.1007/ s00170-004-2435-6.

[11] A. A. Thakre, "Optimization of Milling Parameters for Minimizing Surface Roughness Using Taguchi's Approach", International Journal of Emerging Technology and Advanced Engineering, vol. 3, no. 6, pp. 226-230, Jun. 2013.

[12] S. Sakthivelu, T. Anandaraj, and M. Selwin, "Multi-Objective Optimization of Machining Conditions on Surface Roughness and MRR during CNC End Milling of Aluminium Alloy 7075 Using Taguchi Design of Experiments," Mechanics and Mechanical Engineering, vol. 21, no. 1, pp. 95-103, Jan. 2017.

[13] S. Kumar, I. Saravanan, and L. Patnaik, "Optimization of surface roughness and material removal rate in milling of AISI 1005 carbon steel using Taguchi approach," Materials Today: Proceedings, vol. 22, no. 3, pp. 654-658, Feb. 2020, https://doi.org/10.1016/j.matpr.2019. 09.039 .

[14] L. Ulfiyah, B. Pramujati, and B. O. P. Soepangkat, "Optimization of Tool Wear, Surface Roughness and Material Removal Rate in the Milling Process of Al 6061 using Taguchi and Weighted Principal Component Analysis (WPCA)," Applied Mechanics and Materials, vol. 493, pp. 535-540, Jan. 2014, https://doi.org/10.4028/www.scientific.net/ AMM.493.535.

[15] L. M. Maiyar, R. Ramanujam, K. Venkatesan, and J. Jerald, "Optimization of Machining Parameters for End Milling of Inconel 718 
Super Alloy Using Taguchi Based Grey Relational Analysis," Procedia Engineering, vol. 64, pp. 1276-1282, May. 2013, https://doi.org/ 10.1016/j.proeng.2013.09.208.

[16] V. C. Nguyen, T. D. Nguyen, and D. H. Tien, "Cutting Parameter Optimization in Finishing Milling of Ti-6Al-4V Titanium Alloy under MQL Condition using TOPSIS and ANOVA Analysis," Engineering, Technology \& Applied Science Research, vol. 11, no. 11, pp. 6775-6780, Feb. 2021, https://doi.org/10.48084/etasr.4015.

[17] Q. Xu, J. Zhao, and X. Ai, "Cutting performance of tools made of different materials in the machining of $42 \mathrm{CrMo} 4$ high-strength steel: a comparative study," The International Journal of Advanced Manufacturing Technology, vol. 93, no. 5, pp. 2061-2069, Nov. 2017, https://doi.org/10.1007/s00170-017-0666-6.

[18] M. Elbah, M. A. Yallese, H. Aouici, T. Mabrouki, and J. Rigal, "Comparative assessment of wiper and conventional ceramic tools on surface roughness in hard turning AISI 4140 steel," Measurement, vol. 46, no. 9, pp. 3041-3056, Nov. 2013, https://doi.org/10.1016/ j.measurement.2013.06.018.

[19] L. Chen, Y. Du, P. H. Mayrhofer, S. Q. Wang, and J. Li, "The influence of age-hardening on turning and milling performance of Ti-Al-N coated inserts," Surface and Coatings Technology, vol. 202, no. 21, pp. 51585161, Jul. 2008, https://doi.org/10.1016/j.surfcoat.2008.05.036.

[20] S. K. Khrais and Y. J. Lin, "Wear mechanisms and tool performance of TiAIN PVD coated inserts during machining of AISI 4140 steel," Wear, vol. 262, no. 1-2, pp. 64-69, Jan. 2007, https://doi.org/10.1016/ j.wear.2006.03.052.

[21] Q. Xu, J. Zhao, X. Ai, W. Huang, and G. Wang, "Optimum selection of tool materials for machining of high-strength steels based on fuzzy comprehensive evaluation method," Proceedings of the Institution of Mechanical Engineers, Part B: Journal of Engineering Manufacture, vol. 233, no. 1, pp. 145-153, Jan. 2019, https://doi.org/10.1177/ 0954405417713041 .

[22] M. A. Stipkovic, E. C. Bordinassi, A. D. Farias, and S. Delijaicov, "Surface Integrity Analysis in Machining of Hardened AISI 4140 Steel," Materials Research, vol. 20, no. 2, pp. 387-394, Apr. 2017, https://doi.org/10.1590/1980-5373-MR-2016-0420.

[23] W. Sales, M. Becker, S. B. Clovis, and J. Landre, "Tribological behaviour when face milling AISI 4140 steel with minimum quantity fluid application," Industrial Lubrication and Tribology, vol. 61, no. 2, pp. 84-90, Mar. 2009, https://doi.org/ 10.1108/00368790910940400.

[24] H. Liao and Y. Chen, "Optimizing multi-response problem in the Taguchi method by DEA based ranking method," International Journal of Quality \& Reliability Management, vol. 19, no. 7, pp. 825-837, Jan. 2002, https://doi.org/10.1108/02656710210434766.

[25] S. Nguyen Hong and U. Vo Thi Nhu, "Multi-objective Optimization in Turning Operation of AISI 1055 Steel Using DEAR Method," Tribology in Industry, vol. 43, no. 1, pp. 57-65, Mar. 2021, https://doi.org/ 10.24874/ti.1006.11.20.01

[26] V. V. K. Lakshmi, K. V. Subbaiah, A. V. Kothapalli, and K. Suresh, "Parametric optimization while turning Ti-6Al-4V alloy in Mist-MQCL (Green environment) using the DEAR method," Manufacturing Review, vol. 7, 2020, Art. no. 38, https://doi.org/10.1051/mfreview/2020034.

[27] D. D. Trung, N.-T. Nguyen, D. H. Tien, and H. L. Dang, "A research on multi-objective optimization of the grinding process using segmented grinding wheel by Taguchi-Dear method," Eureka: Physics and Engineering, vol. 1, pp. 67-77, Jan. 2021, https://doi.org/10.21303/24614262.2021.001612.

[28] V. V. Reddy and C. S. Reddy, "Multi Response Optimization of EDM of AA6082 Material using Taguchi-DEAR Method," International Journal of Scientific \& Engineering Research, vol. 7, no. 6, pp. 215-219, Jun. 2016.

[29] "Sandvik Coromant - manufacturing tools \& machining solutions," Sandvik Coromant. https://www.sandvik.coromant.com/en-gb/pages/ default.aspx (accessed Aug. 18, 2021). 